\title{
Identificação e controle com antibióticos de bactérias endofíticas contaminantes em explantes de batata micropropagados ${ }^{(1)}$
}

\begin{abstract}
Jonny Everson Scherwinski Pereira ${ }^{(2)}$, Maria Laura Turino Mattos $^{(3)}$ e Gerson Renan de Luces Fortes ${ }^{(4)}$
Resumo - Este trabalho teve por objetivos isolar, caracterizar e identificar bactérias endofíticas contaminantes encontradas em tecidos de batata durante a micropropagação e selecionar antibióticos para o controle in vitro desses microrganismos por meio da determinação da concentração bactericida mínima inibitória. Brotações de batata apresentando contaminação bacteriana durante a etapa de multiplicação in vitro, foram superficialmente esterilizadas e os internódios transferidos para placas de Petri com ágar nutriente, onde permaneceram incubadas a $28^{\circ} \mathrm{C}$ por até cinco dias. Após purificação, as bactérias foram caracterizadas e identificadas por testes taxonômicos. Um total de oito estirpes bacterianas foram isoladas e identificadas como pertencentes às famílias Acetobacteriaceae (1) e Enterobacteriaceae (2) e aos gêneros Corynebacterium (3), Pseudomonas (1) e Xanthomonas (1). Os melhores resultados para a inibição do crescimento bacteriano foram obtidos com os antibióticos ampicilina, cloranfenicol, estreptomicina e tetraciclina em concentrações que variaram de 32 a $256 \mathrm{mg} \mathrm{L}^{-1}$.
\end{abstract}

Termos para indexação: Solanum tuberosum, contaminação, cultura de tecido, microrganismos.

\section{Identification and antibiotic control of endophytic bacteria contaminants in micropropagated potato explants}

\begin{abstract}
This work aimed to isolate, characterize and identify contaminant endophytic bacteria found in potato tissues during the micropropagation and to select antibiotics for in vitro control of these microorganisms by determining the inhibitory minimal bactericidal concentration. Potato shoots presenting bacterial contamination during the in vitro multiplication were superficially sterilized and the internodes transferred to Petri dishes with nutrient agar medium for up to five days at $28^{\circ} \mathrm{C}$. After subcultures the grown bacteria were purified and identified through taxonomic tests. A total of eight bacterial endophytic strains were isolated and identified as belonging to Acetobacteriaceae (1) and Enterobacteriaceae (2) families and Corynebacterium (3), Pseudomonas (1) and Xanthomonas (1) genera. The best results for bacterial growth inhibition were obtained with ampicilin, chloramphenicol, streptomycin and tetracycline antibiotics in concentrations ranging from 32 to $256 \mathrm{mg} \mathrm{L}^{-1}$.
\end{abstract}

Index terms: Solanum tuberosum, contamination, micropropagation, tissue culture, microorganisms.

\section{Introdução}

Relatos da presença de microrganismos endofíticos em tecidos vegetais têm sido verifica-

\footnotetext{
(1) Aceito para publicação em 14 de abril de 2003.

${ }^{(2)}$ Embrapa-Centro de Pesquisa Agroflorestal do Acre, Caixa Postal 321, CEP 69908-970 Rio Branco, AC. E-mail: jonny@cpafac.embrapa.br

(3) Embrapa-Centro de Pesquisa Agropecuária de Clima Temperado, Caixa Postal 403, CEP 96001-970 Pelotas, RS. E-mail: mattos@cpact.embrapa.br

(4) Embrapa-Centro Nacional de Pesquisa de Recursos Genéticos e Biotecnologia, Caixa Postal 02372, CEP 70770-900 Brasília, DF. E-mail: gerson@ cenargen.embrapa.br
}

dos em relação a um grande número de espécies de plantas (Misaghi \& Donndelinger, 1990; Musson et al., 1995; Raps \& Vidal, 1998). Embora seus efeitos sejam pouco conhecidos, sob condições in vitro, a presença destes microrganismos constitui-se numa das mais importantes causas de perda de material vegetal. Os que tem sido isolados com maior freqüência são os fungos, as leveduras e as bactérias (Leggatt et al., 1988; Leifert \& Woodward, 1998). Geralmente, fungos e leveduras crescem bem em meio de cultura, podendo ser identificada sua presença logo no início do cultivo. Entretanto, os maiores problemas normalmente estão relacionados com as contaminações bacterianas, especialmente aque- 
las que permanecem latentes in vitro, ou seja, não apresentam crescimento visível no meio nem sintomas nos tecidos.

Freqüentemente não se evidencia de imediato a presença de bactérias nas plantas, sendo detectada somente após algum tempo de cultivo, geralmente quando um grande número de plantas já está propagado. Além disso, por serem de difícil visualização, são facilmente transmitidas de um material para outro durante a manipulação dos explantes. Quando as condições do meio de cultura (nutrição, $\mathrm{pH}$ ) tornam-se favoráveis ao seu desenvolvimento, as bactérias passam a competir por nutrientes minerais e carboidratos do meio de cultura, comprometendo a multiplicação e o desenvolvimento dos cultivos, podendo levá-los rapidamente à morte. Esta deterioração dos explantes está relacionada com a produção de metabólitos fitotóxicos pelas bactérias, tais como os ácidos láctico e acético, cianeto, além de certos reguladores de crescimento e antibióticos (Bakker \& Schippers, 1987; Stanier et al., 1987; Kloepper et al., 1989; Leifert et al., 1991).

Do ponto de vista prático, a melhor medida a ser tomada é o descarte e autoclavagem do material contaminado. Contudo, sendo necessária a manutenção do material, podem ser feitos tratamentos curativos com o uso de antibióticos. Usualmente, essas substâncias são incorporadas ao meio de cultura por períodos que variam de dias a meses. Ressalta-se, entretanto, que o sucesso do trabalho com antibióticos somente pode ser obtido após o isolamento, identificação e realização de testes de sensibilidade das bactérias. Por causa da fitotoxicidade e alto custo do tratamento, os antibióticos devem ser utilizados apenas para contaminantes específicos das culturas, pois somente as bactérias que estiverem dentro do espectro de ação de cada antibiótico serão controladas (Leifert et al., 1991; Teng \& Nicholson, 1997).

O presente trabalho teve por objetivos isolar, caracterizar e identificar as diferentes bactérias endofíticas contaminantes encontradas em tecidos de batata durante a micropropagação e selecionar antibióticos para o controle in vitro desses microrganismos por meio da determinação da concentração bactericida mínima inibitória.

\section{Material e Métodos}

Os ensaios foram realizados nos Laboratórios de $\mathrm{Cul}$ tura de Tecidos Vegetais e de Microbiologia Agrícola e do Ambiente da Embrapa-Centro de Pesquisa Agropecuária de Clima Temperado, Pelotas, RS. Plantas de batata das cultivares Astrid, Baronesa e Eliza, com 6 a $8 \mathrm{~cm}$ de altura, apresentando contaminação bacteriana visível durante a etapa de multiplicação em meio de cultura MS, foram coletadas e submetidas à desinfestação por meio de imersão em álcool (70\%) por 15 segundos. Em seguida permaneceram imersas por 15 minutos em solução de hipoclorito de sódio $(1,5 \%)$ com $0,1 \%$ de Tween-80 e foram enxaguadas por três vezes em água destilada esterilizada. De cada porção mediana da planta foi separado um internódio, medindo de 0,3 a $0,5 \mathrm{~cm}$ de comprimento e transferido para placa de Petri com $20 \mathrm{~mL}$ de meio ágar nutriente (AN) (peptona, 5,0 $\mathrm{g} \mathrm{L}^{-1}$; extrato de carne, 3,0 $\mathrm{g} \mathrm{L}^{-1}$; glucose, 5,0 $\mathrm{g} \mathrm{L}^{-1}$; ágar, 15,0 g L${ }^{-1} ; \mathrm{pH} 7,0 \pm 0,2$ ), onde permaneceu incubado a $28 \pm 1^{\circ} \mathrm{C}$ por até cinco dias.

De cada cultivar foram cultivados cinco explantes individualmente. $\mathrm{O}$ tempo de incubação durou apenas o necessário para a visualização do crescimento bacteriano ao redor dos explantes em cultura, o qual foi observado num período de até cinco dias. As colônias foram então repicadas para novo meio de cultura $\mathrm{AN}$ visando à purificação.

As colônias bacterianas foram isoladas com base nas características fenotípicas (pigmentação, superfície, borda, textura) pela técnica de esgotamento por estrias. Em seguida, os isolados foram caracterizados e identificados em nível de família ou gênero por meio de testes bacteriológicos clássicos, como coloração de Gram e motilidade (Humphries, 1974), catalase (MacFaddin, 1980), oxidase (Kovacs, 1956), triplo-ágar-açúcar-ferro (TSI) (Krieg \& Holt, 1984), de fluorescência em meio King B (King et al., 1954, citado por Bradbury, 1988), aerobiose (Bradbury, 1988), endosporos (Leifert et al., 1989), crescimento em meio acidificado ( $\mathrm{pH} 3,6$ e 4,5), asparagina como única fonte de $\mathrm{C}$ e $\mathrm{N}$ e atividade hemolítica (Krieg \& Holt, 1984). A microscopia eletrônica também foi utilizada para observação de uma série de características importantes dos diferentes grupos de bactérias, tais como a forma e arranjo das células bacterianas e presença, localização e tamanho dos flagelos.

Com os resultados dos testes, a identificação foi baseada na classificação sistemática descrita por Krieg \& Holt (1984). Em todos os testes utilizou-se como padrão de comparação as espécies Bacillus megaterium e Pseudomonas fluorescens, pertencentes à coleção de culturas da Embrapa-Centro de Pesquisa Agropecuária de Clima Temperado. 
A suscetibilidade das bactérias isoladas de explantes de batata micropropagados foi testada por meio da prova de sensibilidade por difusão com disco e determinação da concentração bactericida mínima inibitória (MBCMinimal Bactericidal Concentration) (Falkiner, 1988). As suspensões bacterianas utilizadas nos testes foram preparadas colhendo-se um inóculo de cada cultura pura com 18 a 24 horas de crescimento e transferindo-o para erlenmeyer com $50 \mathrm{~mL}$ de meio caldo nutritivo $(\mathrm{CN})$ (peptona, $5,0 \mathrm{~g} \mathrm{~L}^{-1}$; extrato de carne, $3,0 \mathrm{~g} \mathrm{~L}^{-1}$; glucose, $5,0 \mathrm{~g} \mathrm{~L}^{-1}$; pH 7,0 $\pm 0,2$, sem a adição do solidificante ágar); a incubação foi de 24 horas a $28^{\circ} \mathrm{C}$, com agitação a $360 \mathrm{rpm}$.

No teste de sensibilidade por difusão com disco, uma alíquota de $100 \mu \mathrm{L}$ do agente microbiano em estudo foi espalhada sobre a superfície do meio de cultura AN, em placas de Petri. Em seguida, quatro discos de papel (Laborclin ${ }^{\circledR}$ ), impregnados com antibiótico, foram colocados, assepticamente, sobre o meio, sendo as placas então incubadas no escuro a $28^{\circ} \mathrm{C}$. Cada disco foi considerado como uma unidade de observação (repetição).

$\mathrm{O}$ ensaio foi realizado utilizando-se 12 antibióticos $\left(\mu \mathrm{g} \mathrm{mL}{ }^{1}\right)$ : amicacina (30), ampicilina (10), cefoxina (30), cefalotina (30), cloranfenicol (30), eritromicina (15), estreptomicina (10), novobiocin (5), penicilina (10), rifampicina (5), tetraciclina (30) e vancomicina (30).

A sensibilidade do isolado bacteriano ao antibiótico teste foi avaliada após 24 horas de incubação, determinando-se o tamanho do halo de inibição. Foram considerados suscetíveis ao antibiótico os isolados que apresentaram a formação de um halo de inibição de $8 \mathrm{~mm}$, conforme Wilson \& Power (1989).

A determinação da concentração bactericida mínima inibitória foi realizada por meio de diluições seriadas do agente microbiano em meio $\mathrm{CN}$ na presença do isolado bacteriano em estudo. Onze tubos de ensaios com 2,0 mL de meio $\mathrm{CN}$ foram preparados em duplicata e esterilizados em autoclave $\left(15\right.$ minutos sob $121^{\circ} \mathrm{C}$ e $1,5 \mathrm{~atm}$ de pressão). Em câmara de fluxo laminar, as soluções dos antibióticos em teste, esterilizados por filtração (Millipore, $0,22 \mu \mathrm{m}$ ), foram adicionadas individualmente ao meio de cultura de forma a se obter uma diluição seriada de $1 / 2$ a 1/1024, correspondendo a concentrações que variaram de 2,0 a $1.024 \mathrm{mg} \mathrm{L}^{-1}$ do produto testado. O décimo primeiro tubo foi usado como padrão (sem a adição de antibiótico). Em seguida, cada tubo de ensaio recebeu $100 \mu \mathrm{L}$ de uma suspensão bacteriana $\left(10^{-5}\right)$. Por 24 horas, as bactérias foram mantidas a $28^{\circ} \mathrm{C}$ no escuro sob agitação (360 rpm) em erlenmeyers com $50 \mathrm{~mL}$ de meio $\mathrm{CN}$ para crescimento.

A avaliação da turvação do meio de cultura foi feita diariamente por período de até 96 horas. Para confirma- ção dos resultados, as diluições não turvadas dos agentesteste também foram plaqueadas em meio AN, três repetições em placas de Petri, com a avaliação do crescimento feita até 72 horas de incubação.

Os antibióticos empregados foram aqueles que mostraram seletividade aos isolados, de acordo com os resultados obtidos no teste de sensibilidade por difusão em disco: ampicilina, cloranfenicol, eritromicina, estreptomicina, rifampicina e tetraciclina.

\section{Resultados e Discussão}

O crescimento das colônias ao redor dos explantes de batata em ágar nutriente foi observado em até três dias com a maioria das bactérias. Outras, de crescimento mais lento, necessitaram cinco dias em cultivo para que se tornassem visíveis. Foram isolados um total de oito estirpes bacterianas a partir de explantes contaminados de batata das cultivares Baronesa, Eliza e Astrid, oriundas de cultura de tecidos. A coloração das colônias variou entre creme, bege e amarela (Tabela 1). Cinco das estirpes foram gram-negativas (B2, B7A, B7B, B8A e B8B) e somente duas (B2 e B7A) apresentaram crescimento sob condições anaeróbicas. Todos os isolados apresentaram resultado do teste catalase positivo e oxidase negativo. Nenhuma das estirpes formou células de resistência (endosporos) ou apresentou crescimento em meio de cultura com o pH 3,6, atividade hemolítica ou pigmentação fluorescente em meio King B. Os isolados cresceram em pH 4,5; os isolados B2, B7B e B8A não apresentaram crescimento quando a asparagina foi adicionada ao meio de cultura como única fonte de $\mathrm{C}$ e nitrogênio.

Com os resultados obtidos e segundo as chaves classificatórias do Bergey's Manual of Systematic Bacteriology (Krieg \& Holt, 1984), foi possível enquadrar os isolados como membros das famílias Enterobacteriaceae (estirpes B2 e B7A), Acetobacteriaceae (B7B) e dos gêneros Corynebacterium (B3, B4A e B4B), Xanthomonas (B8A) e Pseudomonas (B8B) (Tabela 1). $\mathrm{O}$ contaminante de maior freqüência nas cultivares foi o B2, que, isolado inicialmente da cultivar Astrid, também foi observado nos explantes das cultivares Baronesa e Eliza.

Entre as diferentes espécies pertencentes à família Enterobacteriaceae, o gênero Erwinia constitui- 


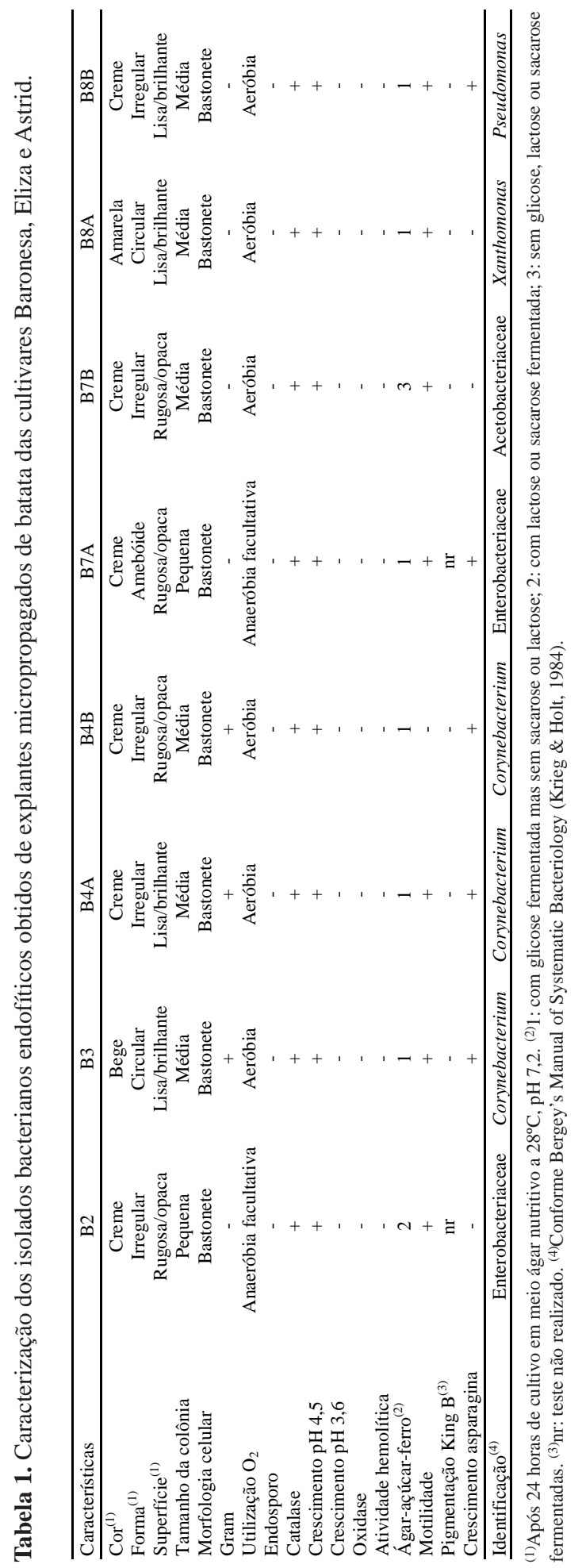

Pesq. agropec. bras., Brasília, v. 38, n. 7, p. 827-834, jul. 2003 
se num dos mais importantes e tem sido relatado por diferentes autores como um dos principais contaminantes na cultura de tecidos (Leifert et al., 1989; Cassells \& Tahmatsidou, 1996; Tanprasert \& Reed, 1998). Embora não tenham sido realizados testes mais específicos para comprovar tal hipótese, é provável que as estirpes isoladas B2 e B7A, classificadas como da família Enterobacteriaceae, pertençam a este gênero. Além de já terem sido isoladas no cultivo de batata in vitro (Long et al., 1988), segundo Krieg \& Holt (1984), todas as espécies do gênero Erwinia estão associadas a plantas, quer como patógenos (causadoras de podridão), saprófitas ou ainda constituintes da flora epifítica. Elas são gram-negativas e apresentam as células em forma de bastonete. Além disso, são anaeróbicas facultativas, não formadoras de esporos e móveis por meio de flagelos peritríquios. Todas essas características foram observadas nos isolados B2 e B7A. Além disso, segundo Romeiro (1995), alguns grupos podem apresentar crescimento mais lento e as colônias serem apigmentadas e opacas em meio de cultura, o que também foi observado durante o seu cultivo. Embora grande parte das espécies deste gênero estejam relatadas com efeitos patogênicos nas plantas, nos testes de hipersensibilidade realizados em plantas de fumo nenhuma reação foi observada.

Bactérias pertencentes ao gênero Corynebacterium também têm sido relatadas como contaminantes in vitro (Leggatt et al., 1988; Leifert et al., 1991). As células bacterianas são gram-positivas, em forma de bastonetes e não esporogênicas. Além disso, são aeróbicas estritas e a coloração das colônias pode variar de branca a amarela ou laranja, o que constitui algumas das principais características das espécies deste grupo (Collins \& Bradbury, 1984). Os três isolados classificados como pertencentes a esse gênero (B3, B4A e B4B) apresentaram essas características. Long et al. (1988) também isolaram e classificaram espécies do gênero Corynebacterium em batata sob multiplicação in vitro e afirmam ser um dos principais contaminantes da cultura.

Segundo Krieg \& Holt (1984) e Stanier et al. (1987), bactérias do grupo Acetobacter apresentamse na forma de bastonetes, gram-negativas, com catalase positiva e reação de oxidase negativa. São normalmente móveis, não esporogênicas e estritamente aeróbicas; seu metabolismo é respiratório, nunca fermentativo. São microrganismos de ocorrência normal em plantas, sendo encontradas abundantemente em material vegetal em decomposição, o que também poderia evidenciar sua ocorrência endógena em plantas.

Os gêneros Xanthomonas e Pseudomonas talvez sejam os mais relatados na literatura como contaminantes de cultivos in vitro (Duhem et al., 1988; Reed et al., 1998; Tanprasert \& Reed, 1998). Espécies do gênero Xanthomonas são móveis, não esporogênicas, gram-negativas, aeróbicas estritas e, usualmente, as colônias são amarelas (Krieg \& Holt, 1984). Além de essas características terem sido observadas no isolado B8A, o que melhor caracterizou o gênero foi a consistência gomosa das colônias em meio de cultura. Possivelmente isto esteja relacionado com a produção de goma xantana, característica das espécies pertencentes a este gênero (Pan et al., 2000). O gênero Pseudomonas engloba grande número de espécies, tanto saprófitas como patogênicas às plantas. Normalmente as bactérias pertencentes a este grupo são móveis, aeróbicas estritas, não esporogênicas e apresentam catalase positiva (Krieg \& Holt, 1984).

O antibiótico que apresentou o maior espectro de ação foi a tetraciclina, proporcionando halo de inibição superior a $8 \mathrm{~mm}$ em seis isolados: B2, B3, B4A, B4B, B7A e B8A (Tabela 2). Nenhum antibiótico mostrou-se eficiente no controle do crescimento da estirpe B7B. Ampicilina, cefalotina, eritromicina e rifampicina, a exemplo da tetraciclina, também apresentaram bons resultados quanto a suscetibilidade dos isolados.

Os outros antibióticos, apesar de proporcionarem para alguns isolados halo de inibição superior a $8 \mathrm{~mm}$, apresentaram menor espectro de ação entre as estirpes, sendo, por isso, desconsiderados nos estudos subseqüentes.

Tais resultados permitiram fazer uma seleção dos antibióticos a serem utilizados para o exame da concentração bactericida mínima inibitória (CBMI). Assim, utilizaram-se para o referido teste os antibióticos ampicilina, eritromicina, rifampicina e tetraciclina. Acrescentaram-se a estes o cloranfenicol, por ter sido o mais eficiente no controle da 
estirpe B8A, e a estreptomicina, pela disponibilidade e por seu controle eficiente sobre diferentes espécies contaminantes in vitro (Wilson \& Power, 1989; Reed et al., 1998).

Nas espécies bacterianas da família Enterobacteriaceae (B2 e B7A), os antibióticos que apresentaram as mais baixas concentrações inibitórias foram a estreptomicina e a tetraciclina. Em ambos, a partir da concentração de $128 \mathrm{mg} \mathrm{L}^{-1}$ não mais se verificou crescimento bacteriano sobre o meio de cultura, após 72 horas de incubação (Tabela 3).

Os isolados do gênero Corynebacterium (B3, B4A e B4B) apresentaram as concentrações míni- mas inibitórias diferenciadas em relação aos antibióticos testados. A mais baixa quanto ao B3 foi a de $256 \mathrm{mg} \mathrm{L}^{-1}$ proporcionada pela ampicilina. Tanto em relação à eritromicina como à rifampicina, a concentração inibitória observada foi de $1.024 \mathrm{mg} \mathrm{L}^{-1}$. A concentração de $32 \mathrm{mg} \mathrm{L}^{-1}$ de tetraciclina foi a que inibiu o crescimento dos isolados B4A e B4B, sendo a mais baixa observada quando comparada com os outros antibióticos testados, ampicilina e eritromicina.

Quando se avaliou a CBMI em relação ao isolado B7B, observou-se que os antibióticos mais efetivos para seu controle foram o cloranfenicol e a

Tabela 2. Sensibilidade de estirpes bacterianas isoladas de batata in vitro a antibióticos em razão do halo de inibição formado $(\mathrm{mm})^{(1)}$.

\begin{tabular}{|c|c|c|c|c|c|c|c|c|c|}
\hline \multirow[t]{2}{*}{ Antibiótico } & \multirow{2}{*}{$\begin{array}{l}\text { Concentração } \\
\left(\mu \mathrm{gL} \mathrm{mL}^{-1}\right)\end{array}$} & \multicolumn{8}{|c|}{ Isolados } \\
\hline & & B2 & B3 & B4A & B4B & B7A & B7B & B8A & B8B \\
\hline Amicacina & 30,0 & $13,0 \mathrm{~s}$ & $4,0 \mathrm{r}$ & $3,5 \mathrm{r}$ & $2,5 \mathrm{r}$ & $10,7 \mathrm{~s}$ & $0,00 \mathrm{r}$ & $7,5 \mathrm{r}$ & $7,2 \mathrm{r}$ \\
\hline Ampicilina & 10,0 & $5,5 \mathrm{r}$ & $9,5 \mathrm{~s}$ & $10,0 \mathrm{~s}$ & $10,2 \mathrm{~s}$ & $10,7 \mathrm{~s}$ & $0,00 \mathrm{r}$ & $0,0 \mathrm{r}$ & $0,0 \mathrm{r}$ \\
\hline Cefoxina & 30,0 & $4,2 \mathrm{r}$ & $4,0 \mathrm{r}$ & $3,5 \mathrm{r}$ & $3,7 \mathrm{r}$ & $8,5 \mathrm{~s}$ & $0,00 \mathrm{r}$ & $1,0 \mathrm{r}$ & $0,0 \mathrm{r}$ \\
\hline Cefalotina & 30,0 & $5,0 \mathrm{r}$ & $9,2 \mathrm{~s}$ & $9,2 \mathrm{~s}$ & $12,7 \mathrm{~s}$ & $9,5 \mathrm{~s}$ & $0,00 \mathrm{r}$ & $0,5 \mathrm{r}$ & $0,0 \mathrm{r}$ \\
\hline Cloranfenicol & 30,0 & $5,2 \mathrm{r}$ & $9,2 \mathrm{~s}$ & $7,2 \mathrm{r}$ & $7,5 \mathrm{r}$ & $7,5 \mathrm{r}$ & $1,00 \mathrm{r}$ & $14,0 \mathrm{~s}$ & $3,7 \mathrm{r}$ \\
\hline Eritromicina & 15,0 & $8,5 \mathrm{~s}$ & $10,5 \mathrm{~s}$ & $10,0 \mathrm{~s}$ & $9,7 \mathrm{~s}$ & $4,7 \mathrm{r}$ & $0,00 \mathrm{r}$ & $10,0 \mathrm{~s}$ & $3,2 \mathrm{r}$ \\
\hline Estreptomicina & 10,0 & $13,2 \mathrm{~s}$ & $4,5 \mathrm{r}$ & $3,2 \mathrm{r}$ & $3,2 \mathrm{r}$ & $8,5 \mathrm{~s}$ & $0,00 \mathrm{r}$ & $0,0 \mathrm{r}$ & $0,0 \mathrm{r}$ \\
\hline Novobiocin & 5,0 & $11,2 \mathrm{~s}$ & $7,2 \mathrm{r}$ & $6,0 \mathrm{r}$ & $8,2 \mathrm{~s}$ & $6,2 \mathrm{r}$ & $0,00 \mathrm{r}$ & $7,0 \mathrm{r}$ & $3,0 \mathrm{r}$ \\
\hline Penicilina & 10,0 & $3,2 \mathrm{r}$ & $6,5 \mathrm{r}$ & $7,2 \mathrm{r}$ & $9,2 \mathrm{~s}$ & $4,7 \mathrm{r}$ & $0,00 \mathrm{r}$ & $0,0 \mathrm{r}$ & $0,0 \mathrm{r}$ \\
\hline Rifampicina & 5,0 & $9,2 \mathrm{~s}$ & $12,5 \mathrm{~s}$ & $11,5 \mathrm{~s}$ & $9,7 \mathrm{~s}$ & $5,2 \mathrm{r}$ & $0,25 \mathrm{r}$ & $6,5 \mathrm{r}$ & $5,0 \mathrm{r}$ \\
\hline Tetraciclina & 30,0 & $16,0 \mathrm{~s}$ & $9,2 \mathrm{~s}$ & $8,2 \mathrm{~s}$ & $8,2 \mathrm{~s}$ & $14,2 \mathrm{~s}$ & $1,20 \mathrm{r}$ & $13,7 \mathrm{~s}$ & $7,7 \mathrm{r}$ \\
\hline Vancomicina & 30,0 & $10,0 \mathrm{~s}$ & $4,7 \mathrm{r}$ & $5,2 \mathrm{r}$ & $5,7 \mathrm{r}$ & $9,5 \mathrm{~s}$ & $0,70 \mathrm{r}$ & $5,2 \mathrm{r}$ & $3,7 \mathrm{r}$ \\
\hline
\end{tabular}

(1)r: resistente (halo < 8,0 mm); s: suscetível (halo $\geq 8,0 \mathrm{~mm}$ ).

Tabela 3. Concentração bactericida mínima inibitória (CBMI) dos antibióticos ampicilina, cloranfenicol, eritromicina, estreptomicina, rifampicina e tetraciclina para as diferentes estirpes bacterianas isoladas de batata sob micropropagação(1).

\begin{tabular}{|c|c|c|c|c|c|c|c|c|c|c|c|c|c|c|c|c|c|c|c|c|c|c|c|c|}
\hline \multirow[t]{2}{*}{ CBMI $\left(\mathrm{mg} \mathrm{L}^{-1}\right)$} & \multicolumn{5}{|c|}{ Ampicilina } & \multicolumn{3}{|c|}{ Cloranfenicol } & \multicolumn{4}{|c|}{ Eritromicina Estreptomicina } & \multicolumn{5}{|c|}{ Rifampicina } & \multicolumn{7}{|c|}{ Tetraciclina } \\
\hline & $\mathrm{B} 2$ & B3 & $\mathrm{B} 4 \mathrm{~A}$ & B4B & $\mathrm{B} 7 \mathrm{~A}$ & B7B & B8A & B8B & B3 & B8A & $\mathrm{B} 2$ & $\mathrm{~B} 7 \mathrm{~A}$ & B3 & B4A & B4B & $\mathrm{B} 7 \mathrm{~B}$ & $38 \mathrm{~B}$ & $\overline{\mathrm{B} 2}$ & $\mathrm{~B} 4 \mathrm{~A}$ & B4B & B7A & $\mathrm{AB} 7 \mathrm{~B}$ & B B8A & B8B \\
\hline 0 & + & + & + & + & + & + & + & + & + & + & + & + & + & + & + & + & + & + & + & + & + & + & + & + \\
\hline 2 & + & + & + & + & + & + & + & + & + & + & + & + & + & + & + & + & + & + & + & + & + & + & + & + \\
\hline 4 & + & + & + & + & + & + & + & + & + & + & + & + & + & + & + & + & + & + & + & + & + & + & + & + \\
\hline 8 & + & + & + & + & + & + & + & + & + & + & + & + & + & + & + & + & + & + & + & + & + & + & + & + \\
\hline 16 & + & + & + & + & + & + & + & + & + & + & + & + & + & + & + & + & + & + & + & + & + & + & + & + \\
\hline 32 & + & + & + & + & + & + & + & + & + & + & + & + & + & + & + & + & + & + & - & - & + & + & + & + \\
\hline 64 & + & + & + & + & + & - & - & + & + & + & + & + & + & + & + & + & + & + & - & - & + & + & + & + \\
\hline 128 & + & + & - & + & + & - & - & - & + & + & - & - & + & + & + & + & + & - & - & - & + & - & - & - \\
\hline 256 & + & - & - & + & + & - & - & - & + & + & - & - & + & + & + & + & + & - & - & - & - & - & - & - \\
\hline 512 & - & - & - & - & + & - & - & - & + & + & - & - & + & + & + & + & + & - & - & - & - & - & - & - \\
\hline 1.024 & - & - & - & - & - & - & - & - & - & - & - & - & - & - & - & - & - & - & - & - & - & - & - & - \\
\hline
\end{tabular}


tetraciclina nas concentrações de 64 e $128 \mathrm{mg} \mathrm{L}^{-1}$, respectivamente. A rifampicina só proporcionou inibição do crescimento quando usada na concentração de $1.024 \mathrm{mg} \mathrm{L}^{-1}$.

Resultados semelhantes aos do B7B foram observados nas espécies dos gêneros Xanthomonas (B8A) e Pseudomonas (B8B), que também tiveram o cloranfenicol seguido da tetraciclina como os mais efetivos produtos para o controle do crescimento nas concentrações mais baixas. Em relação à tetraciclina, ambas bactérias tiveram a CBMI observada em $128 \mathrm{mg} \mathrm{L}^{-1}$. Quanto ao cloranfenicol, a B8A teve seu crescimento inibido na concentração de $64 \mathrm{mg} \mathrm{L}^{-1}$, e na espécie B8B a concentração inibitória foi de $128 \mathrm{mg} \mathrm{L}^{-1}$.

Além do teste onde com discos impregnados com antibiótico, a determinação da CBMI é um dos principais métodos para se avaliar a sensibilidade de bactérias, sendo ambos os testes rotineiramente utilizados para a seleção de antibióticos para o controle de contaminações in vitro (Leggatt et al., 1988; Tanpraset \& Reed, 1998). No presente trabalho, entre os antibióticos testados, os melhores resultados para a inibição do crescimento bacteriano foram obtidos com o cloranfenicol (isolados B7B, B8A e $\mathrm{B} 8 \mathrm{~B})$, estreptomicina (B2 e B7A) e tetraciclina (B2, B4A, B4B, B7A, B7B, B8A e B8B), além da ampicilina, que teve a mais baixa $\mathrm{CBMI}$ para o controle do isolado B3. A amplitude das concentrações que proporcionaram a inibição do crescimento bacteriano variou de 32 a $256 \mathrm{mg} \mathrm{L}^{-1}$, sendo esta última observada para o controle da espécie pertencente ao gênero Corynebacterium (B3).

\section{Conclusões}

1. As bactérias endofíticas isoladas de explantes de batata micropropagados, causadoras de contaminações in vitro, pertencem às famílias Enterobacteriaceae e Acetobacteriaceae e aos gêneros Corynebacterium, Xanthomonas e Pseudomonas.

2. A seleção de antibióticos por meio de testes de sensibilidade por difusão com disco é etapa fundamental para o eficiente controle do crescimento bacteriano in vitro.
3. Os antibióticos ampicilina, cloranfenicol, estreptomicina e tetraciclina em concentrações que variam de 32 a $256 \mathrm{mg} \mathrm{L}^{-1}$ inibem o crescimento de bactérias contaminantes na cultura de tecidos da batata.

\section{Referências}

BAKKER, A. W.; SCHIPPERS, B. Microbial cyanide production in the rhizosphere in relation to potato yield reduction and Pseudomonas spp. mediated plant growth stimulation. Soil Biology and Biochemistry, Oxford, v. 19, n. 4, p. 451-457, 1987.

BRADBURY, J. F. Identification of cultivable bacteria from plants and plant tissue cultures by use of simple classical methods. Acta Horticulturae, Wageningen, v. 225, p. 27-37, 1988.

CASSELLS, A. C.; TAHMATSIDOU, V. The influence of local plant growth conditions on non fatidious bacterial contamination of meristem tips of Hydrangea cultured in vitro. Plant Cell, Tissue and Organ Culture, Dordrecht, v. 47, p. 15-26, 1996.

COLLINS, M. D.; BRADBURY, J. F. Plant pathogenic species of Corynebacterium. In: SNEATH, P. H. A.; MAIR, N. S.; SHARPE, M. E.; HOLT, J. G. (Ed.). Bergey's manual of determinative bacteriology. Baltimore: Williams \& Wilkins, 1984. v. 2, p. 1276-1283.

DUHEM, K.; LE MERCIER, N.; BOXUS, P. Difficulties in the establishment of axenic in vitro cultures of field collected coffee and cacao germplasm. Acta Horticulturae, Wageningen, v. 225, p. 67-75, 1988.

FALKINER, F. R. Strategy for the selection of antibiotics for use against common bacterial pathogens and endophytes of plants. Acta Horticulturae, Wageningen, v. 225, p. 53-56, 1988.

HUMPHRIES, J. Bacteriology. London: J. Murray, 1974. $92 \mathrm{p}$.

KLOEPPER, J. W.; LIFSHITZ, R.; ZABLOTOWICZ, R. M. Free living bacterial inocula for enhancing crop productivity. Trends in Biochemical Science, Amsterdam, v. 7, p. 39-44, 1989.

Pesq. agropec. bras., Brasília, v. 38, n. 7, p. 827-834, jul. 2003 
KOVACS, N. Identification of Pseudomonas pyocyanea by the oxidase reaction. Nature, London, v. 178, p. 703, 1956.

KRIEG, N. R.; HOLT, J. G. (Ed.). Bergey's manual of systematic bacteriology. Baltimore: Williams \& Wilkins, 1984. v. 1.

LEGGATT, I. V.; WAITES, W. M.; LEIFERT, C.; NICHOLAS, J. Characterization of micro organisms isolated from plants during micropropagation. Acta Horticulturae, Wageningen, v. 225, p. 93-102, 1988.

LEIFERT, C.; CAMOTTA, H.; WRIGHT, S. M.; WAITES, B.; CHEYNE, V. A.; WAITES, W. M. Elimination of Lactobacillus plantarum, Corynebacterium spp., Staphylococcus saprophyticus and Pseudomonas paucimobilis from micropropagated Hemerocallis, Choisya and Delphinium cultures using antibiotics. Journal of Applied Bacteriology, London, v. 71, n. 4, p. 307-330, 1991.

LEIFERT, C.; WAITES, W. M.; NICHOLAS, J. R. Bacterial contaminants of micropropagated plant cultures. Journal of Applied Bacteriology, London, v. 67, p. 353 $361,1989$.

LEIFERT, C.; WOODWARD, S. Laboratory contamination management: the requirement for microbiological quality assurance. Plant Cell, Tissue and Organ Culture, Dordrecht, v. 52, p. 83-88, 1998.

LONG, R. D.; CURTIN, T. F.; CASSELlS, A. C. An investigation of the effects of bacterial contaminants on potato nodal cultures. Acta Horticulturae, Wageningen, v. 225, p. 83-91, 1988.

MacFADDIN, J. F. Biochemical tests for identification of medical bacteria. Baltimore: Williams \& Wilkins, 1980. p. $15-16$

MISAGHI, I. J.; DONNDELINGER, C. R. Endophytic bacteria in symptom free cotton plants. Phytopathology, St. Paul, v. 80, p. 808-811, 1990.
MUSSON, G.; McINROY, J. A.; KLOEPPER, J. W. Development of delivery systems for introducing endophytic bacteria into cotton. Biocontrol Science and Technology, Abingdon, v. 5, p. 407-416, 1995.

PAN, A.; MOREIRA, A. S.; VENDRUSCOLO, C. T. Efeito da concentração inicial do inóculo no crescimento celular e qualidade de biopolímeros de Xanthomonas campestris pv. pruni cepa 06. Revista Brasileira de Agrociência, Pelotas, v. 6, n. 3, p. 273-277, 2000.

RAPS, A.; VIDAL, S. Indirect effects of an unspecialized endophytic fungus on specialized plant herbivorous insect interaction. Oecologia, Berlin, v. 114, p. 541-547, 1998.

REED, B. M.; MENTZER, J.; TANPRASERT, P.; YU, $\mathrm{X}$. Internal bacterial contamination of micropropagated hazelnut: identification and antibiotic treatment. Plant Cell, Tissue and Organ Culture, Dordrecht, v. 52, p. 67 70, 1998

ROMEIRO, R. S. Bactérias fitopatogênicas. Viçosa, MG: UFV Imprensa Universitária, 1995. 283 p.

STANIER, R. Y.; INGRAHAM, J. L.; WHEELIS, M. L.; PAINTER, P. R. General microbiology. London: MacMillan, 1987. 689 p.

TANPRASERT, P.; REED, B. M. Detection and identification of bacterial contaminants of strawberry runner explants. Plant Cell, Tissue and Organ Culture, Dordrecht, v. 52, p. 53-55, 1998.

TENG, W. L.; NICHOLSON, L. Pulse treatments of penicillin $\mathrm{G}$ and streptomycin minimize internal infections and have post treatment effects on the morphogenesis of ginseng root culture. Plant Cell Reports, New York, v. 16, p. $531-535,1997$.

WILSON, Z.; POWER, J. B. Elimination of systemic contamination in explants and protoplast cultures of rubber (Hevea brasiliensis Muell. Arg.). Plant Cell Reports, New York, v. 7, p. 622-625, 1989. 